\title{
Project Management of Lightning Protection Innovative Design
}

\author{
Kang Ling ${ }^{1}$ \\ ${ }^{1}$ Weishui Campus, Chang'an University, Weiyang District, Xi'an City, Shaanxi Province, China Xi'an City, Shaanxi Province 710018
}

\begin{abstract}
Lightning protection is becoming more and more important because the climate has changed in recent years and lightning occurs frequently. Given the lightning accidents in these years, this study adopted a new lightning protection device, increased deployment of lightning arresters, solved the problem that the lightning arresters cannot automatically exit the original lightning protection system after penetration. By optimizing the design of the lightning protection system, this study increased the system, reduced the occurrence and damage of lightning accidents. Statistics about the application of the system in an oil production plant show that the system has improved the plant's economic gains. The investment decisionmaking, budget control, phased evaluation and calculation of the innovative project of the lightning protection system have been analyzed in depth. The engineering cost of each item, including the innovative techniques and the application of lightning protection systems, in the project was calculated separately, which improved the cost management of the innovative project.
\end{abstract}

\section{Project investment decision-making}

\subsection{Project investment estimation}

The project budget mainly refers to the preliminary project cost in the feasibility study report during the preparation of the project proposal. Generally, the budget can be made according to the indicators for investment estimation, such as the budget sheet of similar projects, existing equipment, prices of raw materials. Investment estimation is a process of optimizing, evaluating, reviewing, judging the construction costs, and preparing corresponding documents. Investment estimation is the foundation of economic evaluation of engineering projects, a basis for judgement of the feasibility of projects and for final decision-making; it also defines the budget limit of the construction project.

Frequent occurrence of lightning and scientific development has made it possible for development of innovative lightning protection systems. The decision makers in the project team need to assess the budget of the project in terms of the following two aspects: one is the cost for technology research and development, and the other is the cost for system installation and trial operation. After scientific argumentation, calculation, and communication with multi-party, the result of the total cost budget is about 1.1 million yuan.

\subsection{Estimation of the total budget of the project}

Estimation of the total budget refers to the project team's estimation of the various expenses incurred during the whole process of calculating and compiling the project from the beginning to delivery to production or use in the early stage of the project as per the general layout, the project content, the design drawings, and the engineering quantity list. Estimation of the total cost is also called the planned cost of the power engineering product. The approved project cost is a basis for preparing the fixed asset investment plan, the general project contract and the general loan contract; it is also the basis for controlling the basic appropriation and construction drawing budget and evaluating the economic rationality of the design.

Estimation of the total budget in the project design stage: the innovative theory was demonstrated and certified; the project proposal, feasibility study reports, collection technical data were collected; review and certification are carried out to verify the innovation of the project while keeping the technology confidential; and the practical and promotion value of the system is confirmed with the quality and practical functions of the project ensured. The preliminary evaluation of its theoretical innovation and design cost is about 700,000 yuan.

There are five team members involved in innovative lightning protection design project, including two senior engineers, one design engineer, one draft engineer, and one R\&D technician and tester. There are three phases in R\&D and design: concept design phase, feasibility study phase, final design and testing phase.

\section{Budget control of material and installation}

\subsection{Control the cost of materials and equipment}

For the large number of raw materials and equipment used in the lightning protection design innovation project (such as zinc oxide arresters, steel, etc.), we made comparison 
among different suppliers, and finally chose the optimal supplier for procurement. The material cost of power engineering generally accounts for more than $60 \%$ of the entire construction and installation cost, so controlling the expenditure on materials is a key point in the cost control of the construction phase. It is also of great significance for its follow-up engineering application promotion.

\subsection{Auditing and optimizing the site construction plan}

Reviewing and optimizing the construction plan is one of the most effective to control investment especially innovative projects in engineering projects. Before the main project starts, according to the site conditions, we investigated the actual situation compared with the preset plan. We compared the pre-set plan with the actual conditions of the project, and selected among different plans one that is feasible and meets the requirements for timely delivery, quality control and construction cost control. Thus, reviewing and optimizing the plan is an important measure to realize real-time tracking and management of the construction process.

In the actual construction, some old materials are often recycled. For example, if some grounding electrodes are tested and meet the standards, the original grounding electrodes can be used, so the cost for buying a new electrode can be saved.

\subsection{Reviewing and recording}

The records must be clear. The first is to make a record of the preparation work, to determine the rationality of the plan, compliance with expenses standard; the second is to make a record of the work during the construction process. during the construction process, There may be surpluses or changes, whether it is reasonable and meets the regulations and design requirements; the third is to pay attention to the operation records after construction to ensure that could record there may be potential quality or safety risks.

Timey feedback is required during the construction to improve efficiency, reduce working time, save resources, reduce waste, to achieve the optimal control of cost under the premise of ensuring quality.

\subsection{Strict on-site sign-in management}

On-site sign-in is a regular job in project construction. It may cause losses to the project if it is not managed well, especially for innovative projects. Therefore, during the construction process, the resident supervisors and representatives of the construction company should have a high sense of responsibility and mission, and carefully record anything that happens at the construction site. Project managers must often go to the construction site to "sign in as soon as they arrive", and the sign-in also meets the quantitative requirements. For example, for sign-in that record working days, because the number of working days for some jobs is not easy to accurately measure, it can be determined flexibly by contracting, thus avoiding qualitative and ambiguous sign-in. Strict management of on-site sign-in and implementation in accordance with established on-site sign-in management procedures is also an effective way to control unreasonable expenditures of the project, and to prevent spending money in unproductive area.

On-site sign-in should have a reasonable and effective constraint for team member to avoid waste materials and man-hours. In particular, this innovative project needs to be strictly controlled before its promotion, which will serve as a benchmark for subsequent projects. In addition, during the construction of this project, technicians and onsite member need to feedback and communication timely. The sign in system also guarantees the flow of information and the timeliness of feedback.

\subsection{Strictly controlling the engineering changes}

Before construction, it is necessary to organize construction member to visit the site and conduct a joint review of the design drawings. The technicians shall make technical clarifications to the construction person to avoid rework and other low-level errors in the construction, especially for that high cost, intensive innovative knowledge, and irreversible construction, such as grounding electrode construction, lightning protection and disconnected part connection design, etc., must be approved by the designer, Party A's site leader, supervision company, construction company, etc., They need to conduct technical and cost analysis and clarification to minimize rework costs and overspend.

\subsection{Improving contract management and claims management}

Contract management is very important in cost control, and Party A's manager must have deep knowledge for the contract terms. On one hand, the contract clauses can be used to prevent or resolve disputes about project cost at any time; on the other hand, the contract must be fully completed to avoid disputes. They shall be managed in strict accordance with the claim procedures when the construction company's claims for various expenses that are caused by the design or Party A, and resolutely rejected if the unreasonable expenses are caused by the construction company's own reasons.

Precaution is key to contract management. Problems like overdue contracts, violation of terms, temporary increasing costs will lead to changes in construction costs and losses. Through on-site verification, it can be justified. The requirements and changes are the optimal management of contract management and cost control.

\subsection{Strict review of project completion and settlement}

Completion and settlement are the final phase of project implementation. The completion settlement is the project cost prepared by the construction company according to the design drawings and actual changes. It is the basis and voucher for the construction company to settle the project 
price and the proof of the construction company to complete the project output cost. For planned construction projects, completion settlement is the final project cost proposed by the construction company to Party A. Therefore, we must have a responsible attitude to make sure the completion of the project in line with reality, compliance with regulations, and fulfill the contract. Thus, settlement must go through various audit procedures. The key audit content includes the project's quantity, material cost, direct cost, set cost and cost summary. It is necessary to ensure the financial department allocates funds properly, audit the on-site application of the project progress payment at any time, ensure the timely fulfillment of each process in the construction. Project completion settlement is based on verification of the cost of the power project, and it is the basis for compiling the final accounts for the completion of a project and verifying the value of new fixed assets after acceptance of the project. Therefore, completion settlement should be strictly controlled and audited by Party A, the supervision company, and the audit department.

The completion settlement of this innovative lightning protection design project requires the company's decisionmakers, financial department, technical designer, construction party, audit department and other parties to review and confirm that there is no objection before it can be passed and determined. There are no errors or omissions in the progress settlement, cost classification execution of the contract, and it will also serve as a reference sample for the follow-up promotion project.

\section{Features and characteristics of innovative project cost management}

Control and management the project cost is not fixed; it is very complex, requires a management and control must be comprehensive and focused because various changes in the talents, materials and equipment; the changes have made the control and management of project cost more complex. We must fully consider market, personnel quality, actual benefits and effects, and economic thinking to control the cost, fully use of and carefully analyze the important information in the project construction process, and it is necessary to reduce or avoid the loss of project cost also ensure the actual benefits of the project at all phase of project, so that is the highlighted in the utilization of investment funds, and maximized the investment benefits of funds.

It has great intellectual property value in the innovative design and research of lightning protection. Therefore, it is necessary to fully consider its innovative features and promotion value, so that the investment of funds can be well used. Although in the cost control, its intellectual property rights account for a large proportion, in addition to considering its innovation, similar projects can follow this project to transformation and operation, so its promotion value also needs to be carefully considered and evaluated.

During management and control the evaluated of this project, the project's innovative features and scalability characteristics are fully considered, and engineers or technicians are given a larger proportion of profits and relatively loose cost space to ensure its innovative flexibility and matching attributes of intellectual property. Considering its value, this has reached the lowest and most optimized cost control.

\section{Application of the improvement of the lightning protection system}

After in-depth discussion and research online lightning protection system, combined with the current level of lightning protection technology, the following feasible plan were adopted:

(1) There are two types of detachment in field applications: The hot melt type and the hot explosion type. Field test: The hot-melt type release has a longer disconnection time, and the disconnection point is not obvious, and there is still connected some time, while the thermal explosion type disconnector does not have these shortcomings and the test effect is good, so the thermal explosion type disconnector is used.

(2) The resistance of grounding independent lightning protection should be less than $10 \mathrm{ohms}$, and the resistance of grounding independent safety protection should be less than $4 \mathrm{ohms}$. The grounding resistance of the installed lightning arrester was tested, and the grounding resistance of lightning rods, transformers, load switches, etc. were also tested uniformly.

(3) During installation process, construct according to the calculated protection range to ensure that the arrester is fully functional.

(4) In order to solve the current situation of the areas with frequent lightning stroke and key oil production blocks of Xingcai Plant, Xingcai carried out installation and trial operation on Shuangwu Station Line, Hongrong A Line, Hongrong B Line, and Thermal Production Line in 2017.

\section{Safety benefits}

Direct safety benefits: Improve the reliability of line power supply is self-evident for the safety in some important production process. For example, the safety of the strong exhaust system of the heating furnace or the gathering and transportation system is very important. The reliable of the strong exhaust can ensure the safety of the heating furnace. In addition, the reliability and stability of the gathering and transportation system can make the pressure stable enough in pipeline and will never exceed the maximum pressure limit, thus avoiding fire disaster and explosion accidents; in the meantime, this design also avoids some safety accidents such as electric shock and falling from height.

\section{Application effect comparison and economic benefit analysis}

Through improved and implement of the lightning protection system, improved results have been shown in 2017. The annual accident rate of the line is 1.5 times/ (100 
kilometers per year). In 2016, the annual line accident rate was 2.3 times/ (100 kilometers per year). Compared with 2017 and 2016, there were 10 lightning-strike obstacles reduced, 8 accidents reduced, and various power outages reduced by 60 hours, which improved the safety and reliability of the power supply system.

Table 1 Lightning and impact in 2016 and 2017

\begin{tabular}{|c|c|c|c|c|c|}
\hline Years & $\begin{array}{c}\text { Thunderstorm } \\
\text { day (day) }\end{array}$ & $\begin{array}{c}\text { Lightning barrier } \\
\text { (times) }\end{array}$ & $\begin{array}{c}\text { Lightning } \\
\text { accident (times) }\end{array}$ & $\begin{array}{c}\text { Production recovery } \\
\text { time (hours) }\end{array}$ & Remarks \\
\hline 2016 & 23 & 30 & 15 & 150 & \\
\hline 2017 & 37 & 20 & 7 & 90 & \\
\hline
\end{tabular}

Description: The time to resume production refers to the sum of the time for accidental power outage, the time for handling the accident, the time for handling obstacles, and the time for recovering the well.

\section{Project cost budget estimaiton}

\subsection{Technological innovation and design fees}

Since this lightning protection research and design is an innovative applied for the oil field, it has both technological innovation content and extensibility applications, so it is necessary to separately list the technological innovation and design costs.

Table 2 Technological innovation and design cost

\begin{tabular}{|c|c|c|c|c|}
\hline $\begin{array}{c}\text { Serial } \\
\text { number }\end{array}$ & Name & Unit price (yuan) & Quantity & $\begin{array}{c}\text { Total price (ten } \\
\text { thousand yuan) }\end{array}$ \\
\hline 1 & $\begin{array}{c}\text { Scientific thought } \\
\text { innovation fee }\end{array}$ & 20 & 1 & 25 \\
\hline 2 & $\begin{array}{c}\text { Innovation portfolio } \\
\text { design fee }\end{array}$ & 20 & 1 & 15 \\
\hline 3 & Drawing design fee & 10 & 1 & 10 \\
\hline 4 & Application testing fee & 10 & 1 & 10 \\
\hline 5 & Operation monitoring & 10 & 10 & 70 \\
\hline 6 & fee & & & 10 \\
\hline
\end{tabular}

oxide arresters in 2017, with a service life of more than 6 years. At first year: The installation cost is shown in the following table:

\subsection{Installation and investment costs}

Xinglongtai Oil Production Plant installed 350 sets of zinc

Table 3 Year 1: Installation Cost

\begin{tabular}{|c|c|c|c|c|c|}
\hline $\begin{array}{c}\text { Serial } \\
\text { number }\end{array}$ & Name & Unit price (yuan) & Quantity & Total price (yuan) & Remarks \\
\hline 1 & Zinc oxide arrester & 500 & 350 & 175000 & \\
\hline 2 & Thermal explosion & 200 & 350 & 70000 & \\
\hline 3 & Soft copper wire & 30 & 350 & 10500 & \\
\hline 4 & Downline & 80 & 120 & 9600 & \\
\hline 5 & Grounding & 100 & 120 & 12000 & \\
\hline 6 & Assembly processing fee & 20 & 350 & 7000 & \\
\hline 7 & Labor service fee & 500 & $15^{*} 10$ & 75000 & \\
\hline 8 & Vehicle fee & 200 & 40 & 8000 & \\
\hline 9 & Total & & & 367100 & \\
\hline
\end{tabular}




\subsection{Cost ratio chart of various construction costs}

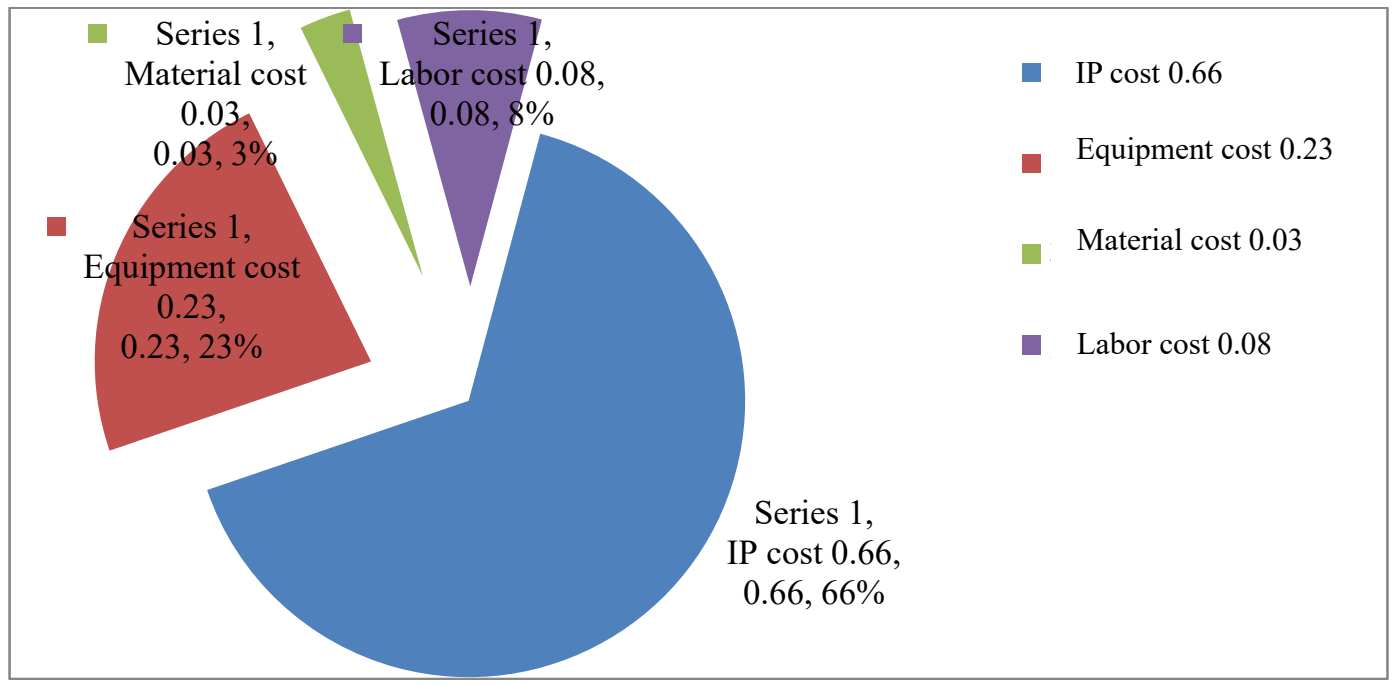

Figure 1: Cost ratio chart of various construction costs

From Figure 1 it can be seen that the innovative lightning protection design project pays more attention to the role of intellectual property in engineering projects in the cost control ratio management, and its proportion is $66 \%$, which fully affirms the innovativeness of technology and intellectual property in engineering important role in the project.

After documenting the investment cost and technologies as well as assessing the application effect of the system, we can reduce the cost of innovation in subsequent steps of construction or development, thereby making the future estimation of project costs economical and rational.

\section{About the Author:}

Kang Ling, female, born in Luliang City, Shanxi Province, China in 2000, undergraduate, now mainly engaged in the study and research of engineering cost

\section{References}

1. Ma Shumin. Analysis on the key points of project cost control[J]. Construction market and bidding, 2006(2).

2. Li Lijuan. Talking about the whole process management of project cost[J]. China Electric Power Education, 2006(2).

3. Sha Lijun. How to strengthen the control and management of project cost[J]. Industrial Auditing and Accounting, 2007(3).

4. Bai Guangliang. Research on Optimizing Lightning Protection System for Power Supply and Distribution Lines[J]. Modern Trade Industry, 2010 (22).

5. A Study on Cost Control in Construction Engineering Project Management [J].] in China Ye Xianghui. Jiangxi Building Materials. 2014(17) 